\title{
White Spot Lesions: An Iatrogenic Damage after Orthodontic Treatment. Its Prevention and Management- An Overview
}

\section{Irfanulla Khan Mahamad ${ }^{1 *}$ and Praveen Kumar Neela ${ }^{2}$}

${ }^{1}$ Assistant Professor, Department of Orthodontics \& Dentofacial Orthopaedics, CKS Teja Institute of Dental Sciences, Tirupati, Andhra Pradesh, India ${ }^{2}$ Assistant Professor, Department of Orthodontics \& Dentofacial Orthopaedics, Kamineni Institute of Dental Sciences, Nalgonda, Andhra Pradesh, India

\begin{abstract}
Enamel decalcifications in the form of white spot lesions is a common negative sequelae of orthodontic treatment in the absence of proper oral hygiene. They appear as small lines along the bracket periphery and in a few patients as large decalcifications with or without cavitations. The presence of white spot lesions after removal of orthodontic appliances is a discouraging finding to a specialty whose goal is to improve facial and dental esthetics. This article examines the prevalence, distribution and formation of white spots after orthodontic treatment and reviews their prevention and management in the post orthodontic phase.
\end{abstract}

Keywords: White spot lesions; Enamel decalcification

\section{Introduction}

Enamel decalcification or white spot lesion (WSL) development of the enamel surface is the most important iatrogenic effect of fixed orthodontic appliance therapy [1]. Orthodontic treatment with multibanded appliance imposes a significant risk for development of WSL. Bands and brackets increase the retention of plaque and food on smooth tooth surfaces that encourages the formation of white spot lesions. Despite intensive efforts to educate patients about effective oral hygiene procedures, enamel demineralization associated with fixed orthodontic appliances remains a significant clinical problem [2]. A review of literature showed $2 \%$ to $97 \%$, of WSL prevalence associated with orthodontic treatment [3-5].

The WSL has been defined as "subsurface enamel porosity from carious demineralization" that presents itself as "a milky white opacity when located on smooth surfaces" [6]. In general, orthodontic patients have significantly more WSLs than non orthodontic patients, and these WSLs may present esthetic problems years after treatment [7]. The literature shows no clear attempt to precisely assess and measure the extent or surface area of such lesions on affected teeth. These studies relied mostly on direct visual scoring. Precise localization of white lesions and their extent on different quadrants in different tooth groups has not been addressed in the literature.

Mizrahi [8] study using the opacity index scoring system showed that the incidence and severity of white spot lesions occurred on both the labial and the lingual surfaces of teeth. There was a significant increase in the prevalence on the cervical and middle thirds of the crowns. The WSLs were more on the cervical and middle thirds of the crowns of the maxillary and mandibular first molars, maxillary lateral incisors, and mandibular lateral incisors and canines, and mainly on the labial surfaces.

Studies have shown that fixed orthodontic appliances induce a rapid increase in the volume of dental plaque and that such plaque has a lower $\mathrm{pH}$ than that in non orthodontic patients [6,7].

The plaque-retentive properties of the fixed appliance predispose the patient to an increased cariogenic risk. Furthermore, there is a rapid shift in the composition of the bacterial flora of the plaque following fixed orthodontic treatment. More specifically, the levels of acidogenic bacteria, such as S. mutans and Lactobacilli become significantly elevated in orthodontic patients. These bacteria produce acid from fermentable carbohydrates and reduce the $\mathrm{pH}$ of the plaque. As the $\mathrm{pH}$ drops below the threshold for remineralization, carious decalcification occurs. The first clinical evidence of this demineralization is visualized as a WSL. Such lesions have been clinically induced within a span of 4 weeks, which is typically within the time period between one orthodontic appointment and the next [8].

\section{Prevention and Management of White Spot Lesions (WSLs)}

\section{Oral hygiene}

The most important prophylactic measure to prevent the occurrence of WSLs in orthodontic patients is implementing a good oral hygiene regimen. Good oral hygiene is thus more important in orthodontic patients treated with fixed appliances than in non treated individuals [2]

\section{Fluoride toothpastes}

As orthodontic patients are at an increased caries risk, appropriate level of fluoride ions is needed to provide an anticaries benefit by promoting enamel remineralization. So for orthodontic patients fluoride concentration below $0.1 \%$ in dentifrices is not recommended [9]. This is because when fluoride ions are incorporated into the surface of enamel, a fluoroapatite crystal structure is formed that has a lower solubility in the oral environment compared with hydroxyapatite. Fluoride toothpastes containing either sodium fluoride, monofluorophosphate, stannous fluoride or a combination of these compounds are recommended.

*Corresponding author: Irfanulla Khan Mahamad, Assistant Professor, Department of Orthodontics \& Dentofacial Orthopaedics, CKS Teja Institute of Dental Sciences, Renigunta Road, Tirupati, Andhra Pradesh, India, Tel: +919844995540; E-mail: drirfankhanmds@yahoo.co.in

Received January 18, 2012; Accepted March 02, 2012; Published March 05 2012

Citation: Irfanulla Khan M, Praveen Kumar N (2012) White Spot Lesions: An latrogenic Damage after Orthodontic Treatment. Its Prevention and ManagementAn Overview. Dentistry 2:123. doi:10.4172/2161-1122.1000123

Copyright: (C) 2012 Irfanulla Khan M, et al. This is an open-access article distributed under the terms of the Creative Commons Attribution License, which permits unrestricted use, distribution, and reproduction in any medium, provided the original author and source are credited. 
In addition to its anticaries activity, stannous fluoride may have a plaque-inhibiting effect by interfering with the adsorption of plaque bacteria to the enamel surface [10]. It was observed that the use of a fluoridated antiplaque toothpaste may reduce enamel demineralization around brackets more than the use of a fluoridated dentifrice alone [11].

\section{Fluoride mouth rinses}

Fluoridated mouth rinses containing $0.05 \%$ sodium fluoride used daily have been shown to significantly reduce lesion formation beneath bands. While the proper use of these products provides the patient with increased caries protection, but patient compliance is required to use mouth rinses. These mouth rinses have been combined with antibacterial agents such as chlorhexidene, triclosan, or zinc to improve their cariostatic effect [12].

\section{Fluoride varnishes}

Since fixed orthodontic appliances induce a high cariogenic challenge, there is a need for more continuous fluoride supplementation independent of patient cooperation. Therefore, some topical fluoride in the forms of varnishes, solutions, or gels may be recommended. The use of fluoride varnishes has proven to be a feasible and safe method of fluoride application. Advantages of the fluoride varnish over other topical fluoride regimens include providing fluoride protection of enamel despite patient noncompliance and delivering the fluoride in a sustained manner over a longer period of time. It has been reported that the application of a fluoride varnish resulted in a $44.3 \%$ reduction in enamel demineralization in orthodontic patients [13].

\section{Recent Advances in Fluorides for Prevention of White Spot Lesions}

\section{Sealants and adhesives}

In general, the duration of orthodontic treatment makes the patient an increased caries risk for a prolonged period of time. As a result, continuous fluoride release from the bonding system around the bracket base would be extremely beneficial. Glass ionomer cements (GICs) were used as orthodontic bonding adhesives to take advantage of their chemical bonding to tooth structure and sustained fluoride release following bonding. In an attempt to increase the bond strengths of GICs, resin particles were added to create resin modified GIC (RMGI) bonding systems. These adhesives release fluoride like conventional GICs but also have higher bond strengths [14]. It was found that lightcured pit and fissure sealants placed on the labial surface adjacent to bonded orthodontic brackets were $80 \%$ effective in preventing demineralization in vitro and required no patient compliance [15].

\section{Antimicrobial agents}

Chlorhexidine is one of the most widely used broad-spectrum antimicrobial agents in dentistry. It has proven to be very effective in the maintenance of plaque control and gingivitis both in the short term and long term studies without developing resistant organisms. Combining chlorhexidene with the bonding primer or applying it after bonding is completed resulted in no significant decrease in shear bond strength and induced antiplaque benefits [16]. More recently, the use of another antimicrobial, cetylpyridinim chloride (CTC), shown to inhibit bacterial growth [17].

\section{Fluoride elastomers}

Several manufactures are marketing elastic ligatures and power chains containing fluoride. Many investigations also suggest that fluoride-releasing elastomeric modules were effective in reducing plaque accumulation and enamel decalcification around the brackets $[18,19]$. Fluoride containing elastomeric ligature ties released significant amounts of fluoride; this was characterized by an initial burst of fluoride during the first 2 days and was followed by a logarithmic decrease over the remainder of the 6 months test period. Fluoride-impregnated elastomeric ligature ties released significantly more fluoride than nonfluoride ties. In the presence of fluoridated toothpaste and mouth rinse the fluoride release is also significantly more. Thus, fluoridated elastomers may imbibe fluoride from their environment [19].

\section{Low fermentable sweeteners}

It has been suggested that xylitol may affect the process of enamel demineralization and remineralization directly [20]. Studies evaluated the influence of a xylitol lozenge on the dental plaque profile of patients with fixed orthodontic appliances. They found that xylitol lozenges can reduce the acidogenicity of dental plaque. The use of sugar free gums is to be recommended after the removal of fixed orthodontic appliances, although as yet we have no quantitative information to indicate a clinically significant beneficial effect over natural remineralization [21].

\section{Argon laser irradiation}

An interesting application of argon lasers in orthodontics involves its ability to alter enamel rendering it less susceptible to demineralization. It was found that the use of argon lasers produce demineralization resistance and might prevent a large percentage of WSLs during the course of treatment [22].

\section{Microabrasion}

Microabrasion has been widely used for the removal of superficial noncarious enamel defects. Recently, this technique has also been advocated for the removal of postorthodontic demineralized white lesions. Studies have shown that microabrasion is an effective treatment approach for the cosmetic improvement of long-standing postorthodontic demineralized enamel lesions [23].

One more recent products introduced are water based, sugar free dental topical cream containing Recaldent ${ }^{\mathrm{TM}}$ CPP-ACP (Caesin Phophopeptide -Amorphous Calcium Phosphate) [24] are used for treatment of mild to moderate White Spot Lesions. Recaldent ${ }^{\mathrm{TM}}$ is derived from the milk protein, casein. For many years it has been known that milk and its derivatives have a tooth protective effect. Recently, research has shown that this activity is due to a part of the casein protein called Casein Phosphopeptide (or CPP), which carries calcium and phosphate ions 'stuck' to it, in the form of Amorphous Calcium Phosphate (or ACP) [25,26]. This complex of CPP-ACP (Recaldent ${ }^{\mathrm{TM}}$ ) is an ideal delivery system for bio-available calcium and phosphate ions. There are products like GC Tooth Mousse [27] which incorporates Recaldent ${ }^{\mathrm{TM}}$. These products will be helpful in protecting the oral environment in a wide range of situations where a mineral imbalance may arise.

\section{Conclusion}

Enamel decalcifications in the form of white spot lesions is a common negative sequelae of fixed orthodontic appliance therapy. 
Citation: Irfanulla Khan M, Praveen Kumar N (2012) White Spot Lesions: An latrogenic Damage after Orthodontic Treatment. Its Prevention and Management- An Overview. Dentistry 2:123. doi:10.4172/2161-1122.1000123

Brackets, bands, arch wires, ligatures, and other orthodontic device increase the retention of plaque and food on smooth tooth surfaces that encourages the formation of white spot lesions. It is therefore of great importance to evaluate the oral hygiene status of patients during the initial months of orthodontic treatment and, if necessary, to implement preventive measures immediately to prevent demineralization.

\section{References}

1. O'Reilly MM, Featherstone JD (1987) Demineralization and remineralization around orthodontic appliances: an in vivo study. Am J Orthod Dentofacial Orthop 92: 33-40.

2. Ogaard B, Rølla G, Arends J (1988) Orthodontic appliances and enamel demineralization. Part 1. Lesion development. Am J Orthod Dentofacial Orthop 94: 68-73.

3. Ogaard B, Larsson E, Henriksson T, Birkhed D, Bishara SE (2001) Effects of combined application of antimicrobial and fluoride varnishes in orthodontic patients. Am J Orthod Dentofacial Orthop 120: 28-35

4. Mitchell L (1992) Decalcification during orthodontic treatment with fixed appliances-an overview. Br J Orthod 19: 199-205.

5. Gorelick L, Geiger AM, Gwinnett AJ (1982) Incidence of white spot formation after bonding and banding. Am J Orthod 81: 93-98.

6. Summitt JB, Robbins JW, Schwartz RS (2006) Fundamentals of Operative Dentistry: A Contemporary Approach. (3rdedn), Hanover Park, IL, Quintessence Publishing 2-4.

7. Ogaard B (1989) Prevalence of white spot lesions in 19-year olds: a study on untreated and orthodontically treated persons 5 years after treatment. Am J Orthod Dentofacial Orthop 96: 423-427.

8. Mizrahi E (1982) Enamel demineralization following orthodontic treatment. Am J Orthod 82: 62-67.

9. Ogaard B, Bishara SE, Duschner H (2004) Enamel effects during bondingdebonding and treatment with fixed appliances, in Graber TM, Eliades T, Athanasiou AE, eds: Risk Management in Orthodontics: Experts Guide to Malpractice. Hanover Park, IL, Quintessence Publishing 30-32.

10. Ogaard B, Gjermo P, Rolla G (1980) Plaque-inhibiting effect in orthodontic patients of a dentifrice containing stannous fluoride. Am J Orthod 78: 266-272.

11. de Moura MS, de Melo Simplicio AH, Cury JA (2006) In-vivo effects of fluoridated antiplaque dentifrice and bonding material on enamel demineralization adjacent to orthodontic appliances. Am J Orthod Dentofacial Orthop 130: 357-363.

12. Ogaard B (2001) Oral microbiological changes, long-term enamel alterations due to decalcification, and caries prophylactic aspects, in Brantley WA, Eliades T, eds: Orthodontic Materials: Scientific and Clinical Aspects. Stuttgart, Thieme 123-142.

13. Vivaldi-Rodrigues G, Demito CF, Bowman SJ, Ramos AL (2006) The effectiveness of a fluoride varnish in preventing the development of white spot lesions. World J Orthod 7: 138-144.

14. Komori A, Ishikawa $H$ (1997) Evaluation of a resin-reinforced glass ionomer cement for use as an orthodontic bonding agent. Angle Orthod 67: 189-195.

15. Frazier MC, Southard TE, Doster PM (1996) Prevention of ename demineralization during orthodontic treatment: An in vitro study using pit and fissure sealants. Am J Orthod Dentofacial Orthop 110: 459-465.

16. Bishara SE, Vonwald L, Zamtua J, Damon PL (1998) Effects of various methods of chlorhexidene application on shear bond strength. Am J Orthod Dentofacial Orthop 114: 150-153.

17. Al-Musallam TA, Evans CA, Drummond JL, Matasa C, Wu CD (2006) Antimicrobial properties of an orthodontic adhesive combined with cetylpyridinium chloride. Am J Orthod Dentofacial Orthop 129: 245-251.

18. Mattick CR, Mitchell L, Chadwick SM, Wright J (2001) Fluoride releasing elastomeric modules reduce decalcification: a randomized controlled trial. J Orthod 28: 217-219.

19. Wiltshire WA (1999) In vitro and in vivo fluoride release from orthodontic elastomeric ligature ties. Am J Orthod Dentofacial Orthop 115: 288-292.

20. Arends J, Christoffersen J, Schuthof J, Smits MT (1984) Influence of xylitol on demineralization of enamel. Caries Res 18: 296-301.

21. Sengun A, Sari Z, Ramoglu SI, Malkoç S, Duran I (2004) Evaluation of the Dental Plaque pH Recovery Effect of a Xylitol Lozenge on Patients with Fixed Orthodontic Appliances. Angle Orthod 74: 240-244.

22. Noel L, Rebellato J, Sheats RD (2003) The Effect of Argon Laser Irradiation on Demineralization Resistance of Human Enamel Adjacent to Orthodontic Brackets: An In Vitro Study. Angle Orthod 73: 249-258.

23. Murphy TC, Willmot DR, Rodd HD (2007) Management of postorthodontic demineralized white lesions with microabrasion: a quantitative assessment Am J Orthod Dentofacial Orthop 131: 27-33.

24. Reynolds EC (2008) Calcium phosphate-based remineralization systems Scientific evidence? Aust Dent J 53: 268-273.

25. Morgan MV, Adams GG, Bailey DL, Tsao CE, Fischman SL, et al. (2008) The anticariogenic effect of sugar-free gum containing CPP-ACP nanocomplexes on approximal caries determined using digital bitewing radiography. Caries Res 42: $171-184$

26. lijima Y, Cai F, Shen P, Walker G, Reynolds C, et al. (2004) Acid resistance of enamel subsurface lesions remineralized by a sugar-free chewing gum containing casein phosphopeptide-amorphous calcium phosphate. Caries Res 38: 551-556.

27. Sudjalim TR, Woods MG, Manton DJ (2006) Prevention of white spot lesions in orthodontic practice: a contemporary review. Aust Dent J 51: 284-289. 